\title{
Transient Cooling of Waxy Crude Oil in a Floating Roof Tank
}

\author{
Jian Zhao, Yang Liu, LiXin Wei, and Hang Dong \\ Key Laboratory of Enhanced Oil and Gas Recovery of Educational Ministry, Northeast Petroleum University, \\ No. 199 Fazhan Road, Souderton Area, Daqing City 163318, China \\ Correspondence should be addressed to Jian Zhao; soulkissing@163.com
}

Received 4 March 2014; Accepted 25 April 2014; Published 5 June 2014

Academic Editor: James Robert Buchanan

Copyright (C) 2014 Jian Zhao et al. This is an open access article distributed under the Creative Commons Attribution License, which permits unrestricted use, distribution, and reproduction in any medium, provided the original work is properly cited.

\begin{abstract}
The transient cooling of waxy crude oil stored in a floating roof tank located in alpine region is studied by means of numerical simulation, accomplished with a two-dimensional model in cylindrical coordinates with the finite volumes method. The typical evolution of transient natural convection and temperature distribution is investigated which can be divided into four stages. For the transient natural convection, it is concluded as the formation, expansion, degradation, and vanishing stage, along with it is the evolution of temperature field regarded as the local cooling, integral cooling, the thermal stratification, and heat conduction course. Special attention is given to the solidified process of waxy oil and its influence on the cooling process of crude oil. Moreover, the effect of tank size, the temperature gradient between oil and ambient, viscosity, and Cp of waxy crude oil on the cooling rate is investigated. The main characteristic of cooling process obtained from numerical results shows a good agreement with the temperature test results from a large floating tank in the oil depot.
\end{abstract}

\section{Introduction}

Safety storage of waxy crude oil is of concern in cold region where ambient temperature may be much lower than the pour point of stored oil. Due to the high wax content, the rheological behavior of crude oil is rather complex and the pour point is high in general, together with the low ambient temperature, leading the probability of oil solidifying be much greater than general condition. The solidifying of crude oil during storage can be a serious accident which hinders the subsequent transportation. In order to avoid this accident, the study of transient cooling process of waxy crude oil in a tank, including the long-term behavior of fluid and heat exchange mechanism with the surroundings, is crucial to the prediction of cooling rate and schedule formulation for transportation and storage.

Only a few studies have been focused on the transient cooling process of oil stored in a tank in a cold environment. Busson and Miniscloux [1] developed a simple model to predict the steady state heat losses from a fuel oil tank based on the assumption of a well-mixed core of fluid. Kumana and Kathari [2] proposed empirical correlations for heat transfer coefficients of the tank and published a model to predict the cooling rate of oil. Based on the numerical method,
Venart et al. [3] solved the governing natural convection equations to investigate the steady state heat losses from a fuel oil tank with a constant viscosity fluid assumption. Cotter and Charles successively presented three papers [46]; they solved the governing mass, momentum, and energy conservation equations numerically in stream function vorticity form by employing a control volume finite difference method. Thus, the flow pattern and temperature distribution of transient cooling by natural convection were discussed. After that, the effect of heat transfer coefficient, aspect ratio, and temperature dependent viscosity on the fluid flow and heat transfer was examined. Finally, a simplified heat loss model was given. Although Cotter's research gave a beneficial investigation on this subject, the object of his research is dome roof tank. The heat loss rate at the sidewall is largest. Thus, the flow pattern and temperature distribution are significantly affected by the heat transfer at sidewall. However, nowadays, benefiting from the technical and economic advantages, the floating roof tank has become the preferred facility to store oil in large crude oil depot. Most quantity of heat has been lost through the tank roof which is constituted by doubledeck steel plate that clings to the surface of oil due to the poor thermal insulation. Instead, the sidewall has become the minor location for heat loss attributing to the insulation. 
The mode of natural convection and heat transfer induced by this specific is much different from that in the dome roof tank. Besides, in Cotter's papers, their study focused on the early stages of cooling; however, as the cooling process develops, the flow structure and temperature distribution vary significantly for the deteriorative rheological behavior of waxy crude oil. De Césaro Oliveski et al. [7] presented a numerical and experimental analysis of the thermal stratification and natural convective regime inside a small tank containing thermal oil. In their research, the sidewall was still taken as the primary heat loss position; the top and bottom were considered as perfectly insulated which gave a similar conclusion as Cotter's research. In addition, all the properties of crude oil were assumed constant. But in fact, the variable viscosity can significantly affect the natural convection of oil. Zhao [8] studied the temperature changing rule of crude oil by numerical simulation. Meanwhile, the difference among wavelet finite element method, traditional finite element method, and actual measurement was also examined. But the effect of natural convection which can be a great factor to the heat transfer was not presented in his research. And the properties of oil were still taken as constant. Based on a modified $k$-e model, Vardar [9] analyzed the filling process of a fuel oil storage tank containing a higher temperature fuel oil numerically; the streamlines, the isotherms, and the transient average temperature variations were presented. But the cooling process in his research is much different from the static storage process of crude oil.

Another area of study that has analogies to the problem is the transient cooling of water in a thermal tank. The literature on the subject presents many experimental and numerical simulation works [10-18]. Among these studies, Nelson et al. [12] presented experimental studies on thermal stratification in chilled-water storage systems by a fiberglass storage tank in static and dynamic modes of operation. In their paper, emphasis was given to the effects of mixing at the inlet, leading to the definition of the mixing coefficient. Rodríguez et al. [15] investigated the transient cooling of fluid initially at rest inside a vertical cylinder. The relevant nondimensional groups that defined the unsteady natural convection were identified. A parametric study was carried out to correlate the Nusselt number and the transient mean fluid temperature. Finally a prediction model based on global balances was proposed. Oliveski et al. [16, 17] analyzed the transient temperature distribution and flow structure by numerical simulation and experimental approaches. A correlation was developed between the Nusselt number, the volume, and aspect ratio of tank and heat loss. The properties difference between crude oil and water is rather significant, especially for the waxy crude oil. During cooling process, the non-Newtonian fluid rheological behavior can significantly affect the characteristic of cooling process. Nevertheless, due to the similar geometry and boundary of heat transfer, the existing research for water tank can definitely provide some beneficial enlightenment and reference for the transient cooling problem of waxy crude oil.

As mentioned above, the study of cooling process of waxy crude oil in a floating roof tank has not been reported in the literature. The aim of this work is to investigate the flow

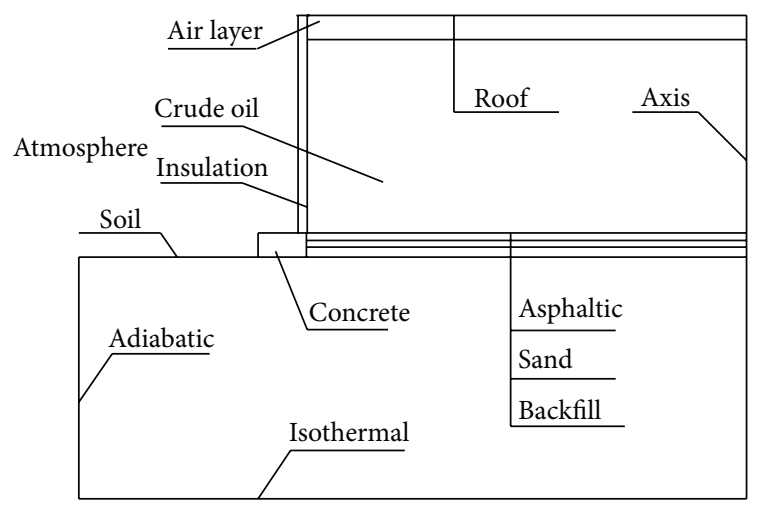

Figure 1: Physical model.

pattern and heat transfer characteristic induced by unsteady natural convection during a long-term cooling process of waxy crude oil in a floating roof tank by means of numerical simulations. In order to characterize this cooling process more distinctly, the cooling process has been divided into four stages according to the variation of natural convection. At each stage, the profiles of temperature and flow structure have been presented. In addition, the effect of tank size, ambient temperature, and oil properties on the cooling rate has been analyzed.

\section{Problem Definition}

The research object is a double deck floating roof tank; the fluid and surrounding solid medium are considered as a whole computational domain, which is illustrated in Figure 1. The roof of the tank is constituted by two thin steel plates with an air interlayer between them. Although the thermal conductivity of air is rather small, the heat conducting property is enhanced by the natural convection in the enclosure space. To simplify this heat transfer process, an equivalent thermal conductivity of $0.7 \mathrm{~W} / \mathrm{m} \cdot \mathrm{K}$ is introduced based on test result from a floating roof tank. Because of the large thermal conductivity, two thin steel plates are neglected during simulation. And other accessories on the roof are also neglected.

The sidewall is considered insulated, and the thermal conductivity of insulation material is $0.038 \mathrm{~W} / \mathrm{m} \cdot \mathrm{K}$, and the density of $40 \mathrm{~kg} / \mathrm{m}^{3}$ is imposed. The specific heat capacity is $1600 \mathrm{~J} / \mathrm{kg} \cdot \mathrm{K}$. For the bottom of tank, the foundation is composed by variety of materials and is placed on the soil. The properties of various materials are listed in Table 1 . The foundation is surrounded by the ring wall made by concrete.

By virtue of axial symmetry geometrical feature, a twodimensional model is used. In the axial direction, the external surface of the tank roof is taken as third kind boundary condition. The ambient temperature and external heat transfer coefficient are imposed. The isothermal layer of soil is described as another boundary with a constant temperature. In the radial direction, except for the axisymmetric boundary, the soil far from the tank is regarded as adiabatic boundary. The external surface of the sidewall of the tank and the surface 
TABLE 1: Physical properties of different materials.

\begin{tabular}{lccc}
\hline Material & $\begin{array}{c}\text { Thermal conductivity } \\
(\mathrm{W} / \mathrm{m} \cdot \mathrm{K})\end{array}$ & $\begin{array}{c}\text { Density } \\
\left(\mathrm{kg} / \mathrm{m}^{3}\right)\end{array}$ & $\begin{array}{c}\text { Specific heat capacity } \\
(\mathrm{J} / \mathrm{kg} \cdot \mathrm{K})\end{array}$ \\
\hline $\begin{array}{l}\text { Asphaltic } \\
\text { sand }\end{array}$ & 0.5 & 1400 & 1000 \\
Sand & 0.56 & 1500 & 837 \\
Backfill & 0.93 & 1750 & 1062 \\
Concrete & 1.63 & 2500 & 1170 \\
Soil & 1.74 & 1600 & 1750 \\
\hline
\end{tabular}

of soil are all taken as third kind boundary conditions, the same as the tank top.

The waxy crude oil from Daqing oil field was presented as working fluid. In order to describe the thermophysical properties more precisely, the variable property model was used. As the cooling process continues, the wax components will precipitate, which affects the fluid property of oil. To represent the effect of slight wax components precipitate, the viscosity-temperature relationship at low shear rate tested by rheometer was used to simulate the fluid property effect by natural convection, as shown in Figure 2. The Cptemperature relationship was introduced to reflect the variation of $\mathrm{Cp}$ changing with temperature, as shown in Figure 3. Due to the latent heat of slight wax components precipitate, no remarkable variation is shown in fluid characteristic, except that the $\mathrm{Cp}$ increases slightly with the temperature dropping. When the temperature drops so significantly that mass individual precipitation of wax components is achieved, the net structure of wax components begins to form which hinders the flow of oil prominently. Besides, the latent heat obtained by precipitation of wax components will be pronounced and will slow down the cooling process. In order to represent these physical properties, the porosity hypothesis was introduced. The liquid-solid mushy zone made by the mass precipitation of wax components is treated as a porous zone with porosity equal to the liquid fraction, and appropriate momentum sink terms are added to the momentum equations to account for the pressure drop caused by the presence of wax-crystal structure. Specifically, when the temperature of oil is higher than the losing flow point, the porosity is defined as 1 and the sink terms are taken as 0 ; the viscosity-temperature and Cp-temperature relationships defined above are used. When the oil is so cold that the driving force by density difference hardly overcomes the waxcrystal structural strength and the convection vanishes, the porosity is 0 . The mushy zone is a region which temperature is between the above two points, and the liquid fraction and porosity lie between 0 and 1 . A linear relationship based on the liquid fraction versus temperature relationship is used. Besides, the independent latent heat changing with porosity is contained in the energy equation. For the crude oil used in the simulation, the two temperature points are $30^{\circ} \mathrm{C}$ and $24^{\circ} \mathrm{C}$. The density of crude oil at $20^{\circ} \mathrm{C}$ is $0.85 \mathrm{~g} / \mathrm{cm}^{3}$, and the coefficient of thermal expansion is $0.000844 \mathrm{~K}^{-1}$.

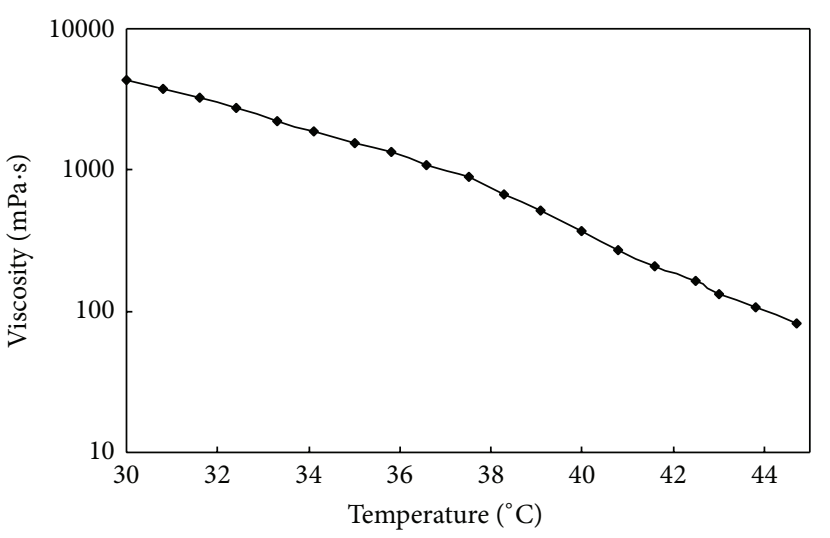

FIGURE 2: Viscosity versus temperature for oil.

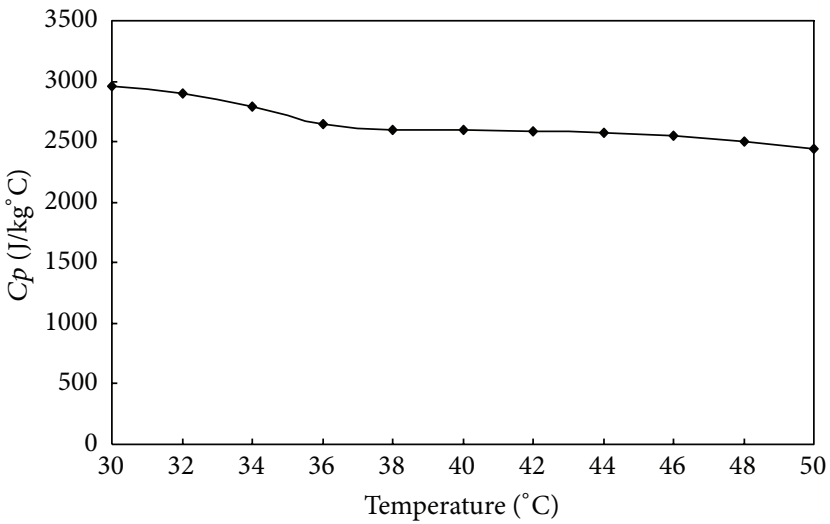

FIgURE 3: Specific heat versus temperature for oil.

\section{Mathematical Model}

3.1. Governing Equations. The fluid flow and heat transfer phenomena involved in the transient natural convection inside a storage tank are governed by the continuity, momentum, and energy conservation equations. In view of the existence of solid materials, the differential equation of heat conduction is involved. Taking into account the range of size and temperature difference between oil and ambient in the present work, the hypothesis of laminar flow has been considered. By considerably extending the range of parameters studied, higher Rayleigh number may be obtained. But the driving force decreases as the tank contents cool and the crude oil appears more viscous, especially in the region near wall. Thus the convection becomes weak and the laminar flow regime is certain to exist. Besides, according to the research from Lin and Armfield [19], it is expected that the result from high Rayleigh number showed to have the same general behavior as that observed in lower Rayleigh number studies, however, with considerably more activity. So the simulation based on laminar flow model is performed. Due 
to the axial symmetry, the governing equations in axial and radial directions are written as follows:

$$
\begin{aligned}
& \frac{\partial \rho_{o}}{\partial t}+\frac{\partial\left(\rho_{o} u\right)}{\partial z}+\frac{1}{r} \frac{\partial\left(\rho_{o} r v\right)}{\partial r}=0 \\
& \frac{\partial\left(\rho_{o} u\right)}{\partial t}+\frac{\partial\left(\rho_{o} u u\right)}{\partial z}+\frac{\partial\left(\rho_{o} v u\right)}{\partial r} \\
& =-\frac{\partial p}{\partial z}+\mu\left(\frac{\partial^{2} u}{\partial z^{2}}+\frac{1}{r} \frac{\partial u}{\partial r}+\frac{\partial^{2} u}{\partial r^{2}}\right)-\rho_{o} g+S_{u} \\
& \frac{\partial\left(\rho_{o} v\right)}{\partial t}+\frac{\partial\left(\rho_{o} u v\right)}{\partial z}+\frac{\partial\left(\rho_{o} v v\right)}{\partial r} \\
& =-\frac{\partial p}{\partial r}+\mu\left(\frac{\partial^{2} v}{\partial z^{2}}+\frac{1}{r} \frac{\partial v}{\partial r}+\frac{\partial^{2} v}{\partial r^{2}}-\frac{v}{r^{2}}\right)+S_{v} \\
& S_{u}=-\frac{(1-\beta)^{2}}{\left(\beta^{3}+0.001\right)} C_{m} \cdot u \\
& S_{v}=-\frac{(1-\beta)^{2}}{\left(\beta^{3}+0.001\right)} C_{m} \cdot v \\
& T>T_{s}, \quad \beta=1 \\
& T<T_{z}, \quad \beta=0 \\
& T_{z}<T<T_{s}, \quad \beta=\frac{T-T_{z}}{\left(T_{s}-T_{z}\right)} \\
& \frac{\partial\left(\rho_{o} H\right)}{\partial t}+\frac{\partial\left(\rho_{o} u H\right)}{\partial z}+\frac{\partial\left(\rho_{o} v H\right)}{\partial r} \\
& =k_{o}\left[\frac{\partial^{2} T}{\partial z^{2}}+\frac{1}{r} \frac{\partial T}{\partial r}+\frac{\partial^{2} T}{\partial r^{2}}\right] \\
& H=h+\Delta H \\
& h=h_{\mathrm{ref}}+\int_{T_{\mathrm{ref}}}^{T} c_{\mathrm{po}} d T \\
& \Delta H=\beta L \\
& \frac{\partial\left(\rho_{i} T\right)}{\partial t}=\frac{k_{i}}{C_{\mathrm{pi}}}\left[\frac{\partial^{2} T}{\partial z^{2}}+\frac{1}{r} \frac{\partial T}{\partial r}+\frac{\partial^{2} T}{\partial r^{2}}\right],
\end{aligned}
$$

where $\rho_{o}, \mu, c_{\mathrm{po}}$, and $k_{o}$ are the density, $\mathrm{kg} / \mathrm{m}^{3}$, dynamic viscosity, Pas, the specific heat at constant pressure, and the thermal conductivity of crude oil, respectively. $\rho_{i}, c_{\mathrm{pi}}$, and $k_{i}$ are the density, the specific heat at constant pressure, and thermal conductivity of solid material. $z, r$ are the axial and radial coordinate, $\mathrm{m} . u, v$ are the axial and radial velocity, $\mathrm{m} / \mathrm{s}$. $\beta$ is the porosity. $T_{z}$ is the temperature when the driving force hardly overcomes the wax-crystal structural strength. $T_{s}$ is the losing flow point when the yield stress appears. $S_{u}, S_{v}$ are the momentum sink terms derived from the Darcy law accounting for the pressure drop caused by the presence of wax-crystal structure. $C_{m}$ is the constant measures the amplitude of the damping. The higher this value is, the steeper the transition of the velocity of the material to zero is as it solidifies. The choosing of $C_{m}$ depends on the nature of flow in mushy region with wax-crystal structure; $10^{4}$ is chosen for this simulation. $h$ is the sensible enthalpy. $h_{\text {ref }}$ is the reference enthalpy. $T_{\text {ref }}$ is the reference temperature. $\Delta h$ is the latent heat associated with the porosity and $L . L$ is the latent heat at temperature higher than losing flow point.

3.2. Boundary and Initial Conditions. For the top and sidewall exposing in atmosphere, the boundary conditions are imposed as

$$
\begin{aligned}
& -k_{i} \frac{\partial T_{b}}{\partial z}=h_{\mathrm{ding}}\left(T_{b}-T_{a}\right) \\
& -k_{i} \frac{\partial T_{b}}{\partial r}=h_{\mathrm{bi}}\left(T_{b}-T_{a}\right) .
\end{aligned}
$$

The boundary on the radial direction of soil is defined as adiabatic boundary and expressed as

$$
-k_{i} \frac{\partial T_{b}}{\partial r}=0
$$

On the axial direction, the isothermal boundary of soil is composed on the isothermal layer:

$$
T_{b}=T_{h} .
$$

The axis of the computational domain is defined as

$$
-k_{i} \frac{\partial T_{b}}{\partial r}=0,
$$

where $h_{\text {ding }}$ and $h_{\mathrm{bi}}$ are the extern convection heat transfer coefficients computed by the correlations for forced convection heat transfer on condition that the ambient temperature and wind speed were known. $T_{b}$ is the temperature on boundary, $T_{a}$ is the ambient temperature, and $T_{h}$ is the temperature of soil isothermal layer.

The cooling process is assumed to start from an initial condition of still and uniform oil temperature. The temperature distribution of solid is determined by the oil and ambient temperature following a steady heat transfer course.

3.3. Numerical Procedure. Based on finite volumes techniques [19], the governing equations together with the boundary conditions have been discretized into algebraic equations systems. During the spatial discretization course, diffusive terms have been evaluated using central differences scheme, while convective terms have been approximated by means of QUICK scheme [20]. For the temporal discretization course, the implicit first order accurate method has been used. The pressure implicit with splitting of operators (PISO) pressure-velocity coupling algorithm has been used which performs an additional correction to improve the efficiency of pressure-velocity coupling calculation [21, 22]. Especially for the transient problems, PISO has the significant advantage in calculation efficiency. Based on the above methods, the specific solution was achieved by the numerical calculation code written by the authors. 


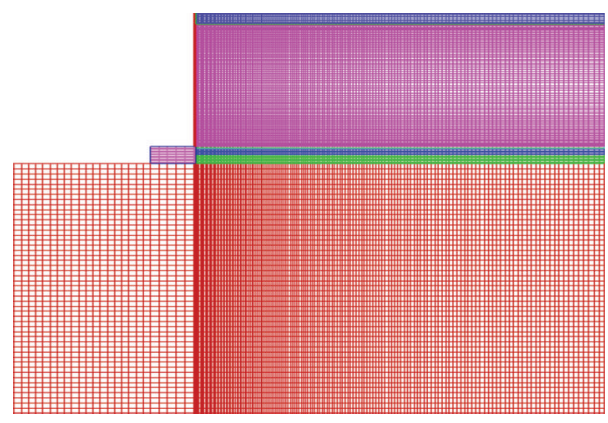

FIgURE 4: Computational grids.

The computational grid used to divide the domain into discrete control volumes for condition 9 is shown in Figure 4; the depth of soil isothermal layer is $12.5 \mathrm{~m}$ and $5 \mathrm{~m}$ away from the concrete wall is taken as the radial adiabatic boundary of soil. Managed by structured grid method, the quadrilateral grid element was used, constructing nonuniform 600 volume elements grid in the radial direction and 320 volume elements grid in the axial direction inside the tank. Because of the large gradients of the temperature and velocity, the grid refinement at the sidewall, top, and bottom of tank was achieved. In order to analyze the influence of the grid on computational cost and the solution, three additional grids have also been tested, including $240000(600 \times 400), 217600(680 \times 320)$, and $145600(520 \times 280)$; the grid refinement strategy is also different. Performing the steady natural convection on the sidewall and top as testing cases concluded that the grid $192000(600 \times 320)$ created above is suitable. Except for the oil zone, the computational domain considered also includes the roof, the insulation material of the sidewall, the soil, and foundation below the tank in order to investigate the unsteady heat transfer behavior of the solid material and its influence on the temperature distribution of oil. Due to the large number of control volumes of the model, a multigrid method was used to accelerate the convergence of the solver. The convergence criterion was lower than $10^{-6}$ for the residual of energy and $10^{-3}$ for momentum and continuity equations.

\section{Results and Analysis}

In an attempt to investigate the general characteristic of flow and heat transfer of waxy crude oil in a floating roof tank, twelve working conditions have been established, more details are shown in Table 2.

\subsection{Typical Evolution of Transient Natural Convection and} Temperature Field. Based on the numerical solutions of different working conditions, the typical evolution of transient natural convection and temperature field have been investigated which can be divided into four stages. For the transient natural convection, it can be concluded as the formation, expansion, degradation, and vanishing stage, along with it is the evolution of temperature field which can be regarded as the local cooling, integral cooling, the thermal stratification, and heat conduction course. To illustrate the
TABLE 2: Main parameters for different working conditions.

\begin{tabular}{lccccc}
\hline Condition & $\begin{array}{c}\text { Diameter } \\
(\mathrm{m})\end{array}$ & $\begin{array}{c}\text { Height } \\
(\mathrm{m})\end{array}$ & $\begin{array}{c}\text { Ambient } \\
\text { temperature } \\
\left({ }^{\circ} \mathrm{C}\right)\end{array}$ & $\begin{array}{c}\text { Initial } \\
\text { temperature } \\
\left({ }^{\circ} \mathrm{C}\right)\end{array}$ & $\begin{array}{c}\text { Wind } \\
\text { speed } \\
(\mathrm{m} / \mathrm{s})\end{array}$ \\
\hline 1 & 5.7 & 1.2 & -20 & 42 & 7.9 \\
2 & 5.7 & 1.2 & -40 & 42 & 7.9 \\
3 & 5.7 & 1.2 & -20 & 38 & 7.9 \\
4 & 5.7 & 1.2 & -40 & 38 & 7.9 \\
5 & 11.4 & 3.6 & -20 & 42 & 7.9 \\
6 & 11.4 & 3.6 & -40 & 42 & 7.9 \\
7 & 11.4 & 3.6 & -20 & 38 & 7.9 \\
8 & 11.4 & 3.6 & -40 & 38 & 7.9 \\
9 & 24 & 7 & -20 & 42 & 7.9 \\
10 & 24 & 7 & -40 & 42 & 7.9 \\
11 & 24 & 7 & -20 & 38 & 7.9 \\
12 & 24 & 7 & -40 & 38 & 7.9 \\
\hline
\end{tabular}

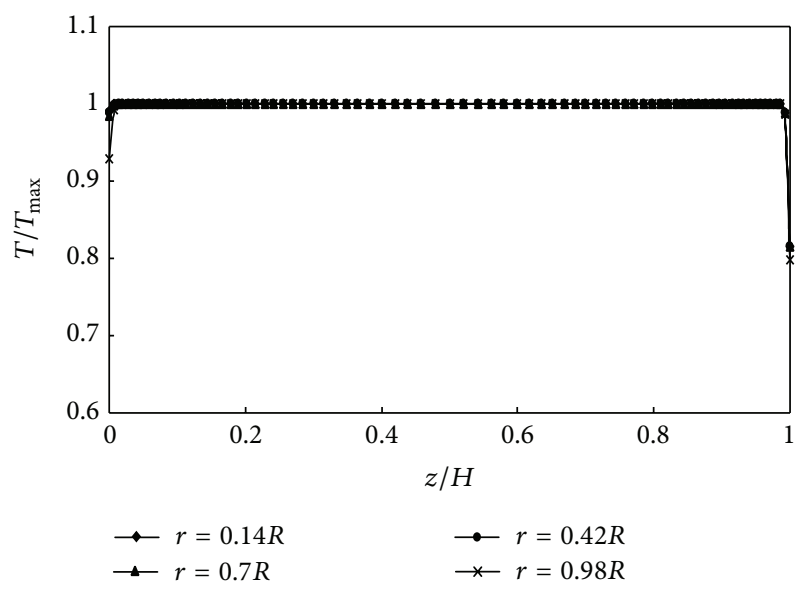

FIgURE 5: Profile of axial dimensionless temperature.

transient evolution of temperature and velocity features at different instants during the cooling process, the simulation result of condition 1 was taken as representative.

4.1.1. The Formation of Natural Convection. At the first instant, due to the heat loss on the boundaries, the temperature of oil near walls drops rapidly, but the temperature of oil elsewhere is nearly unchanged; the axial temperature profile on different radial coordinate is shown in Figure 5, in which $R$ and $H$ represent the radius and liquid level of the tank and $T_{\max }$ is the initial temperature of oil. Due to the heat loss from the top and sidewall at the same time, the oil at the top sidewall corner cools most rapidly, thus the oil there becomes relatively more dense and begins to travel down along the sidewall. At the same time the hot oil in the core of the tank moves towards the area the cold oil once occupied. So the transient convection starts and the boundary layer develops rapidly on the sidewall, as illustrated in Figure 6. Figure 7 is the profile of axial velocity along the axial direction. By the influence of this initial convection, the 


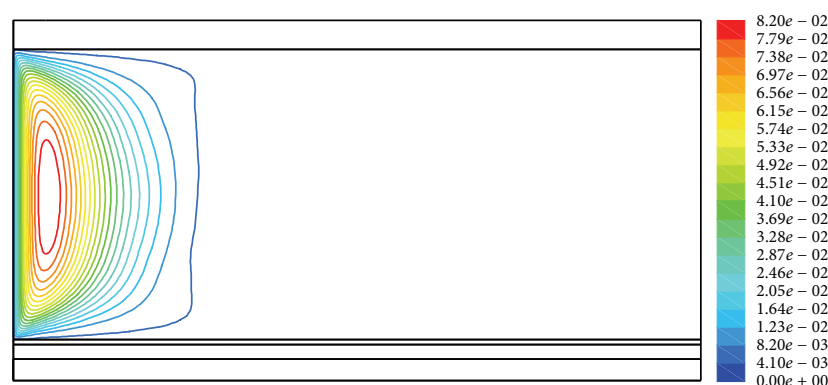

FIGURE 6: Contours of stream function field.

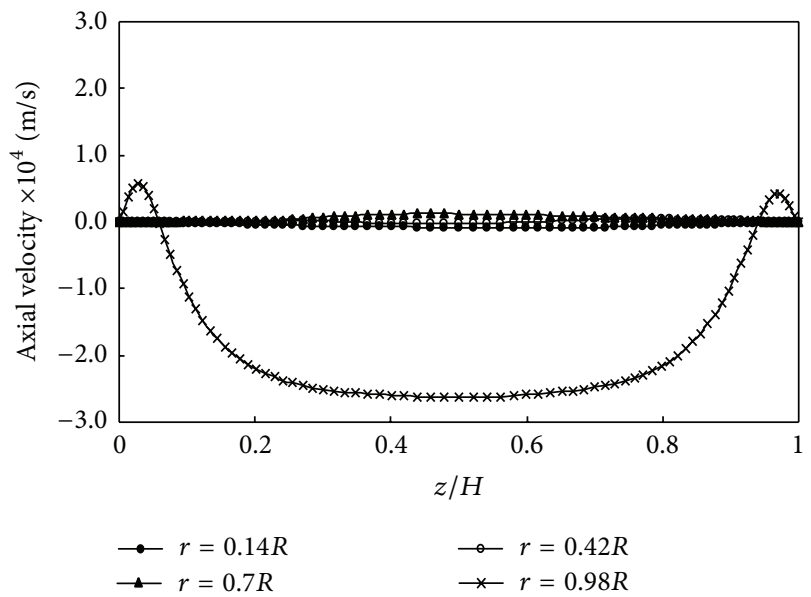

FIGURE 7: Profile of axial velocity along axial direction.

temperature of oil at the bottom sidewall corner becomes the lowest on bottom. As the cooling process goes on, the temperature of oil near the top wall drops more significantly; the clue of the convection from top wall to bottom is already there. But at this moment there are just some convection cells formed near the top wall and the interaction between the cold and hot oil is just confined to some small regions, which can be seen in Figure 8. According to this chart, the influence from the top convection cells to the large convection cell near the sidewall seems significant, which makes the profile of axial velocity near sidewall different from the previous condition, as illustrated in Figure 9. Due to this influence, the correlations for the natural convection on erect wall proposed by the former researchers may not be suitable again. In Figure 10 how the temperature distribution on the radial direction in the tank is shown; it is worth noting that near the top wall the profile of temperature shows some apparent fluctuation corresponding to the convection cells. No matter the radial or axial direction of the tank, only the temperature of certain position near walls drops apparently. The temperature in the center of the tank is nearly unchanged, the oil temperature becomes lower in the region where are getting closer to the wall. At this moment, the top sidewall corner is the lowest temperature region in the tank.

4.1.2. The Expansion of Natural Convection. As time marches, the region where moving fluid occupies continues to expand

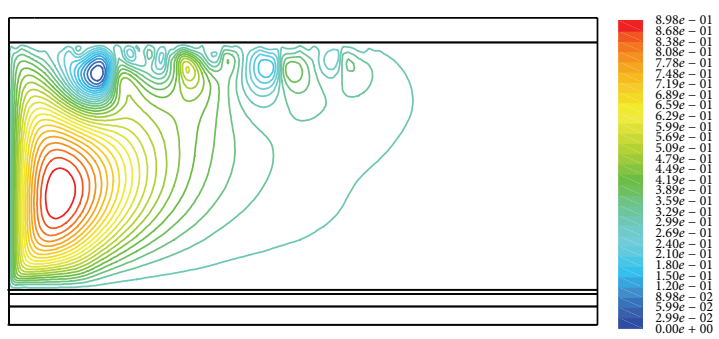

Figure 8: Contours of stream function field.

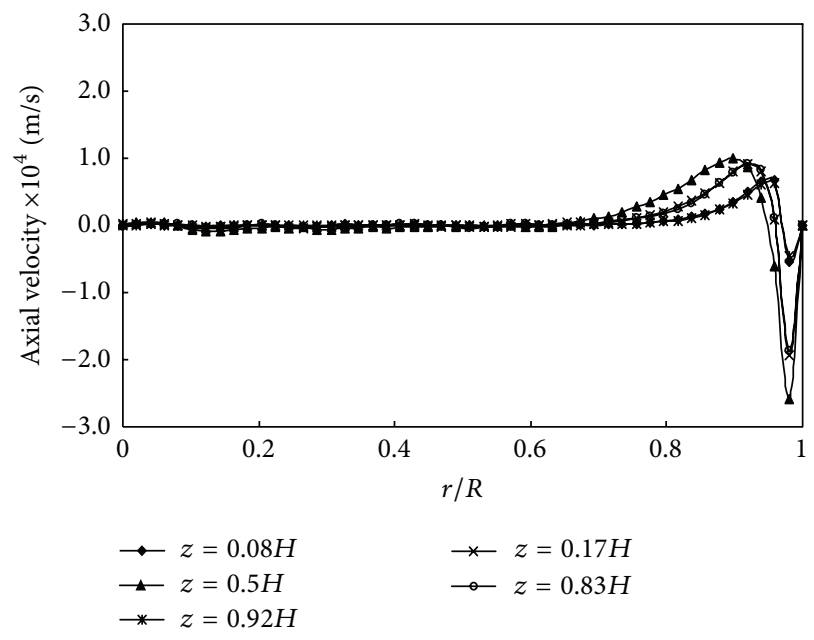

FIgURE 9: Profile of axial velocity along radial direction.

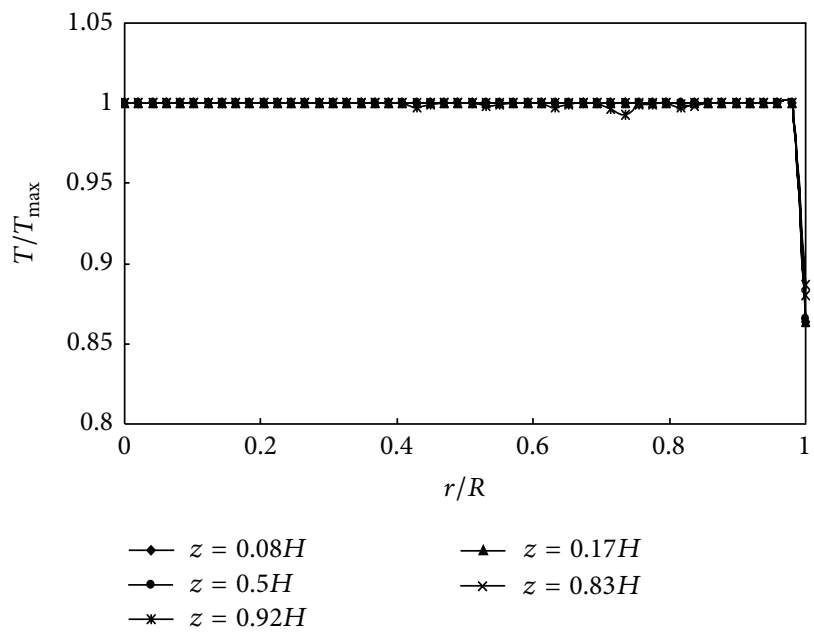

FIGURE 10: Profile of radial dimensionless temperature.

dramatically; the previous formed small convective cells begin to combine and transform as time goes by. Finally the region where the interaction between cold and hot oil occupies almost covers the totality of the tank volume; the whole region of oil nearly starts to move. The cold oil once formed at the top wall at the previous stage has accomplished completed migration process from top to bottom. Figure 11 shows the contours of stream function field. There are 


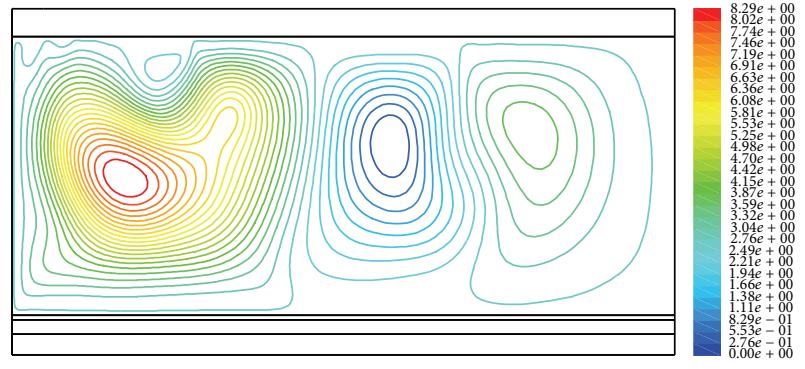

FIGURE 11: Contours of stream function field.

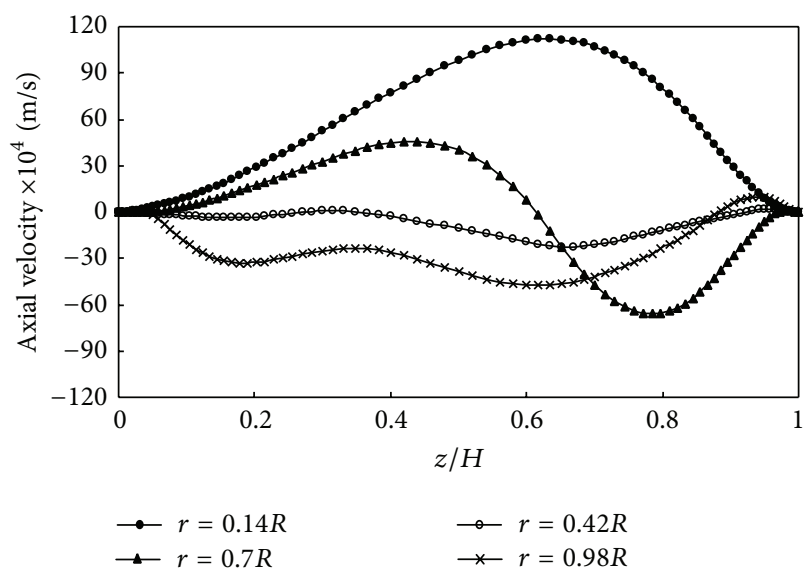

FIgURE 12: Profile of axial velocity along axial direction of tank.

apparently three large convection cells formed in the tank; the velocity magnitude overall becomes much larger than last stage, especially in the center of the tank, as illustrated in Figure 12. Due to the low temperature near the sidewall, the velocity magnitude of $0.98 R$ is not increased as fast as other positions. Since the heat loss at top wall is much larger than that at the sidewall, the flow pattern from this cooling scenario is mainly described as the macroscopic convection from top to bottom. Due to the extensive heat exchange between the hot and cold oil, the fluid in the tank core begins to cool as well. At this stage, except for the oil near wall, the temperature of most of the oil drops rapidly as a whole.

4.1.3. The Degradation of Natural Convection. As the cold oil descends, the temperature distribution of crude oil appears thermal stratification, which can be mainly divided into three regions in the axis direction, as illustrated in Figure 13. Near the top wall, the temperature of oil there is the lowest because of the largest heat loss; but due to the convection, the coverage of cold oil near top wall is smaller than that near bottom where the cold temperature layer is the thickest and thermal stratification is most significant, as shown in Figures 13 and 14. Due to the convection of cold and hot oil in the center of the tank, the temperature of oil in the center is still the highest and is still homogeneous, but an apparent temperature drop compared to last stage can be found. As the viscosity of waxy oil sensitively changes with temperature, the viscosity of oil increases rapidly near walls due to the low

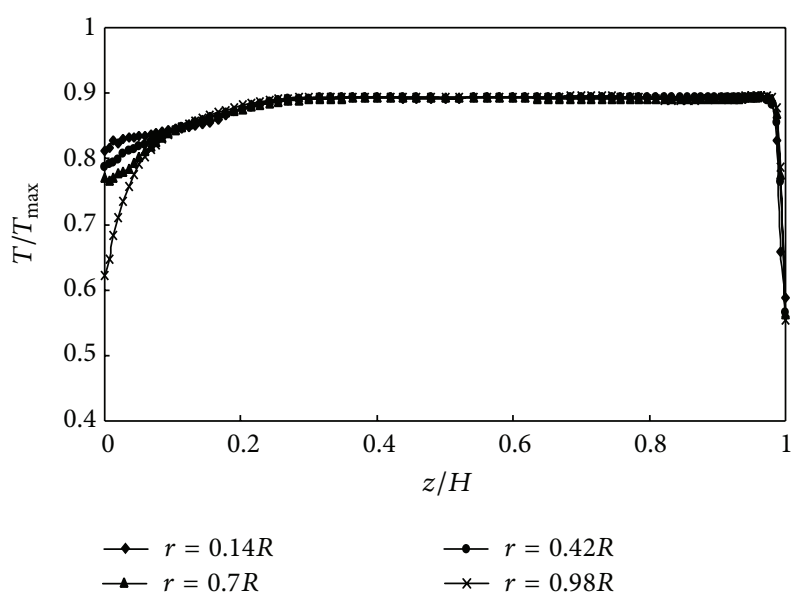

Figure 13: Profile of axial dimensionless temperature.

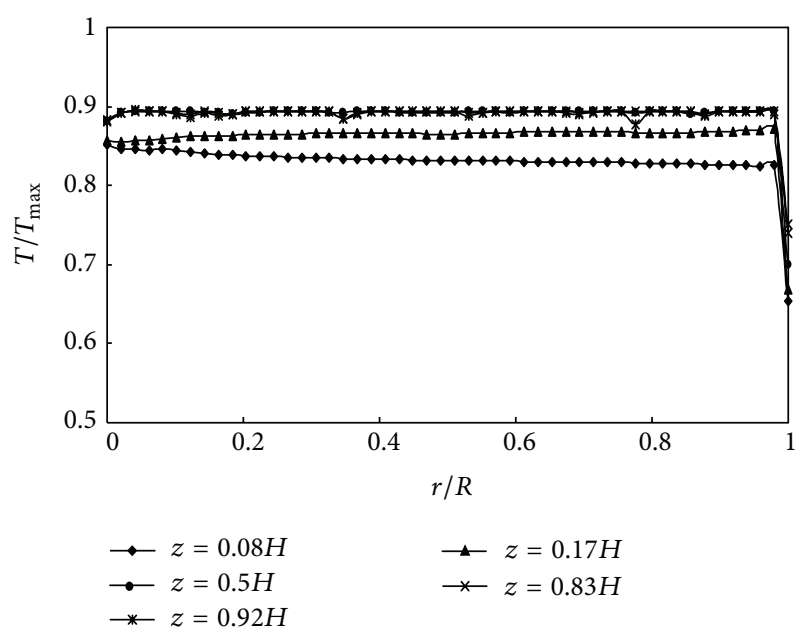

FIGURE 14: Profile of radial dimensionless temperature.

temperature, leading the convection to degrade significantly, which is shown in Figures 15 and 16. Near the top and bottom walls, the oil nearly stops moving; only the oil in the center of the tank has prominent velocity magnitude. Compared to last stage, the mean temperature continues to drop and the mean velocity magnitude of oil significantly decreases. As the cooling process marches, the thermal stratification continues to develop for the decrease of driving buoyancy forces, leading the cold region to enlarge and the core area to reduce gradually where the natural convection occupies.

Due to the presence of wax-crystal structure, the flow pattern of natural convection has changed. The surface of solidified crude oil has become the new boundary of the interior convection. As clearly shown in Figure 17, the numerical value represents the porosity. The magnitude 0 represents the solidified crude oil, and the magnitude 1 represents the oil which has free movement. The corresponding velocity field in Figure 18 shows that the natural convection once existed on the sidewall has shifted to the surface of solidified crude oil. 


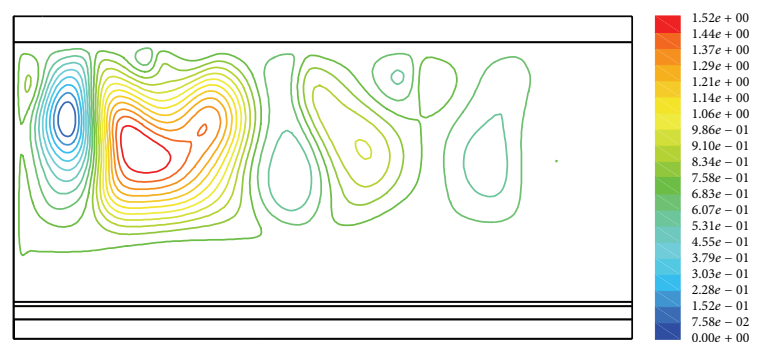

FIGURE 15: Contours of stream function field.

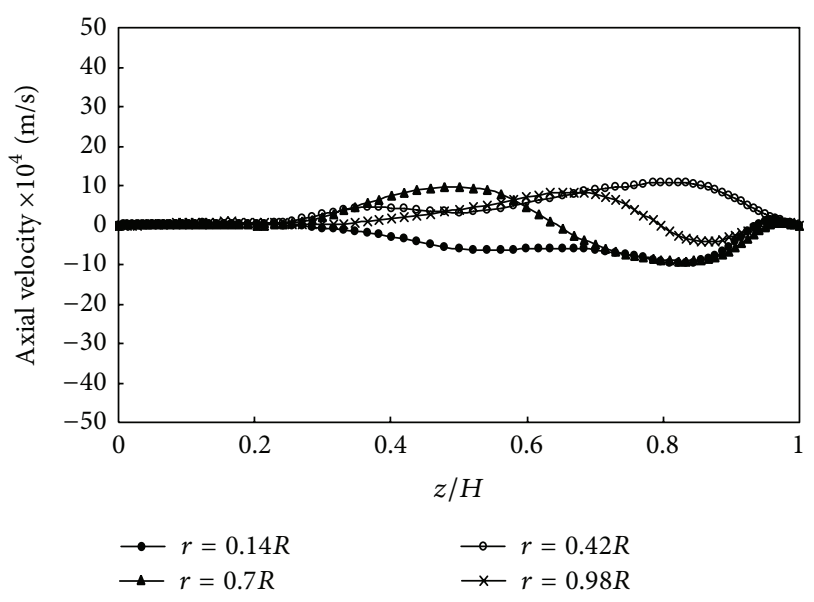

FIGURE 16: Profile of axial velocity along axial direction.

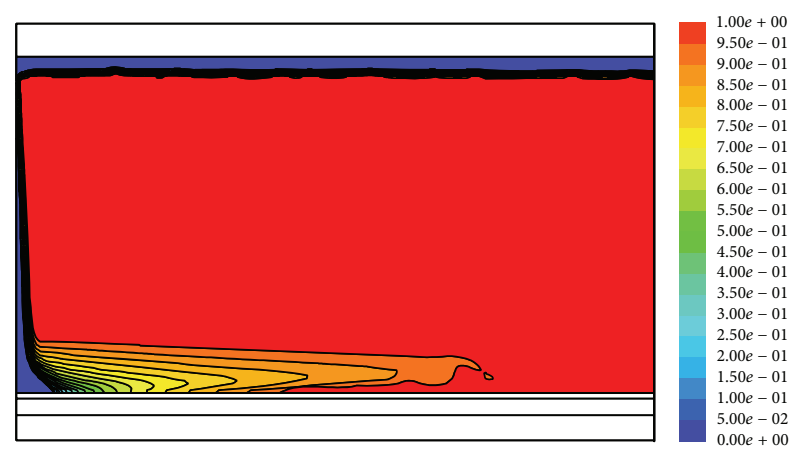

FIGURE 17: Distribution of solidified crude oil.

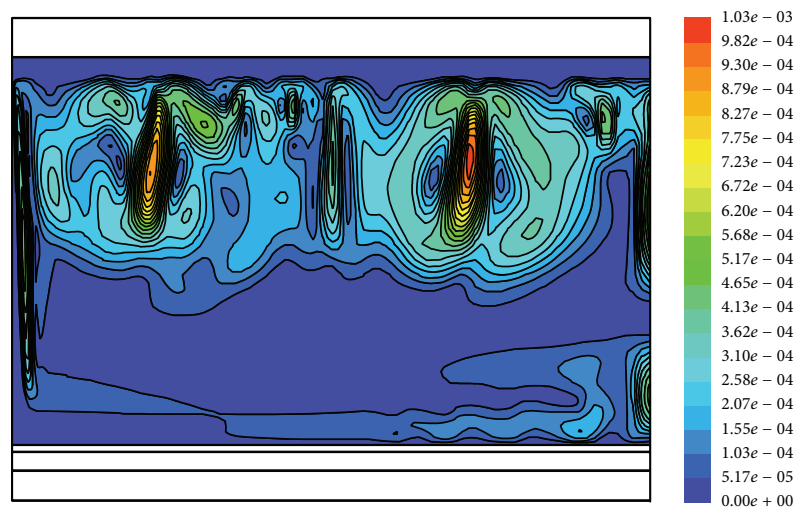

FIGURE 18: Contours of velocity field.
4.1.4. The Vanishing of Natural Convection. With the temperature continuing to drop, the wax components in crude oil continue to precipitate. The natural convection in the cold region near walls firstly begins to cease attributing to the low temperature, after that the region will enlarge till the totality of the tank volume is contained. When that stage comes out, the heat conduction will become the sole heat transfer form. Besides, with the wax composition separating out, the latent heat continues to release. Both variations slow down the cooling rate of oil and the temperature stratification appears more evident. Throughout the whole cooling process, the development of solidified oil region can be illustrated in Figure 19.

As it is shown in Figure 19, at the first instant, due to the large heat loss, the solidified oil mostly forms near the top wall but distributes sporadically. Besides, because of the convection at the sidewall the solidified crude oil forms at the bottom sidewall corner. After that, the solidified crude oil develops together and step by step covers the top surface. At the same time, the solidified oil at the bottom sidewall corner enlarges in two forms. On one hand, the solidified crude oil expands along the bottom wall to the center of it. On another hand, solidified oil expands along the sidewall and gradually covers the wall. Finally the solidified crude oil near walls forms the solidified layer structure, which is most concentrated at the bottom sidewall corner; a regular and thick solidified layer exits at the top wall; at the sidewall the solidified layer presents a solidified structure with relatively thinner thickness in the upper part and gradually incrassating along the sidewall towards the bottom. In the bottom part of the tank, especially far from the sidewall, most regions are covered by the mushy crude oil which is the mixture of solidified and liquid oil and occupy a large part of the tank height. The existence of solidified crude oil slows down the cooling rate, partly because of the thermal resistance, and the latent heat is another significant reason. During the cooling process of waxy crude oil, the first and second stages last very short time; most time is occupied by the third and fourth stages. In the fourth stage, the cooling rate is the lowest and presents the longest period. But this stage is regarded as an accident and is forbidden in the actual crude oil storage process. Thus, the third stage presents the most usual condition during the actual storage process of waxy crude oil.

4.2. The Effect Factor on the Cooling Rate of Waxy Oil. The mean temperature of crude oil is defined as follows:

$$
T_{\mathrm{avt}}=\frac{1}{V_{t}} \cdot \int T d V
$$

In Figure 20, it is shown how the tank size influences the cooling rate of oil. Although the heat loss area is enlarged with the increasing tank size, the increasing mass of oil can significantly slow down the cooling rate, and the heat loss of unit mass oil decrease in the mean time. The volume of tank changes from $30.6 \mathrm{~m}^{3}$ (condition 1) to $367 \mathrm{~m}^{3}$ (condition 5) and $3165 \mathrm{~m}^{3}$ (condition 9). The mean temperatures of oil after 60 hours are $27.1^{\circ} \mathrm{C}, 35.2^{\circ} \mathrm{C}$, and $38.5^{\circ} \mathrm{C}$, which indicates 


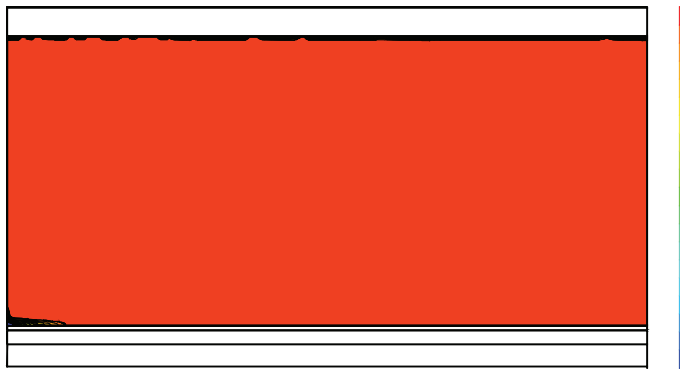

(a) 9 hours

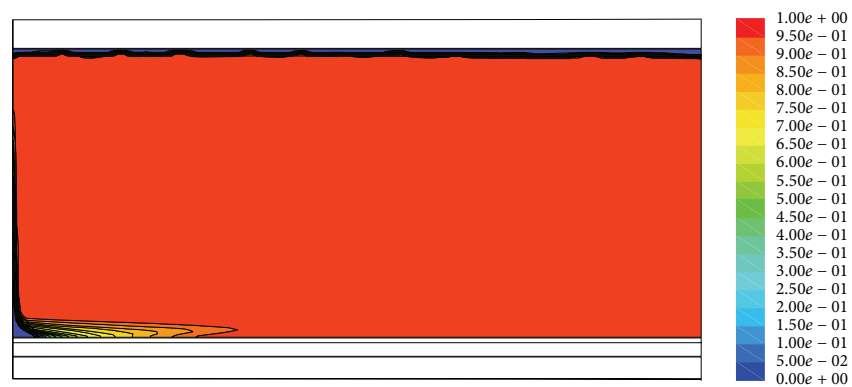

(b) 11 hours

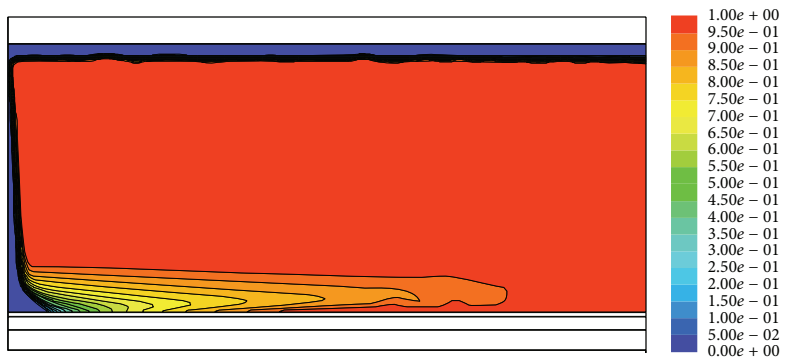

(c) 28 hours

FIGURE 19: The evolution of solidified oil region.

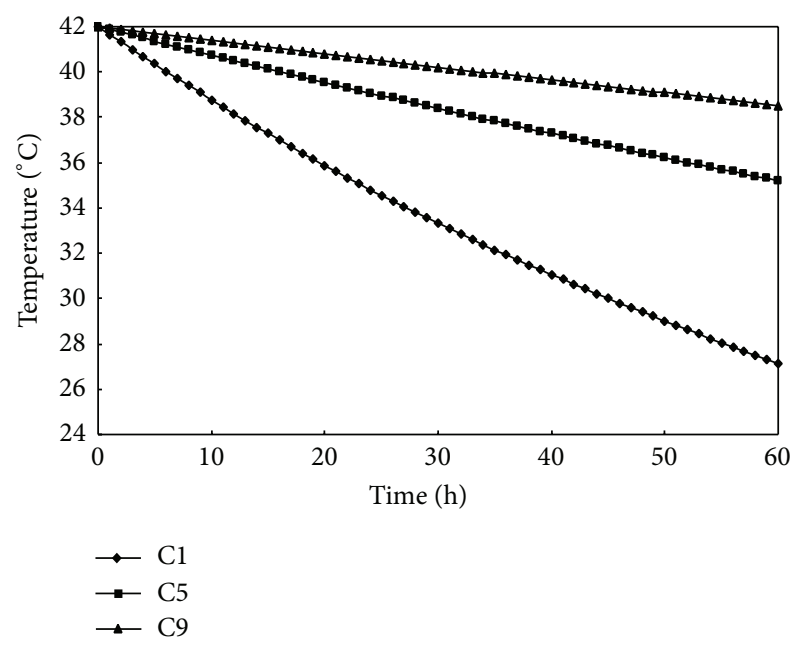

FIGURE 20: The evolution of mean temperature versus tank size.

that with the increase of tank size, the cooling rate largely slows down. Moreover, when the tank size gets smaller, the influence of tank size appears more apparent; thus the influence is estimated to be weak when the tank size enlarges to some point. At the moment, large floating roof oil tank is getting more and more widely used, which improves the centralization management extent. The low heat loss may be another important factor. However, for the large tank size, especially the large tank diameter, the increasing heat loss area of tank roof can significantly weaken the insulation effect. So increasing the tank height presents to be more effective for energy saving.

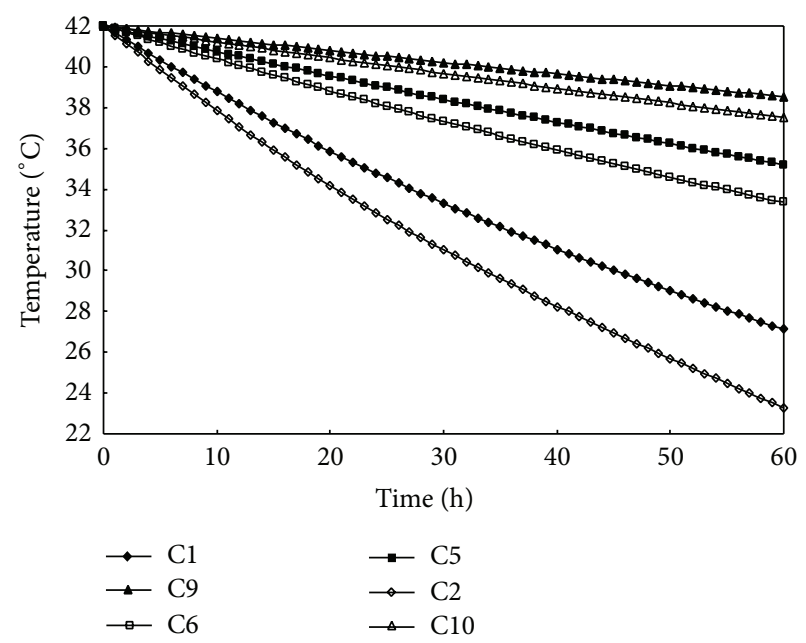

FIgURE 21: The evolution of mean temperature versus ambient $T$.

For the same tank size, the temperature gradient between oil and ambient becomes the most important factor that affects the cooling rate. With the increasing temperature difference, the cooling rate of oil becomes higher. Figure 21 shows the different mean temperature variation by comparing condition 1 and condition 2, condition 5 and condition 6 , and condition 9 and condition 10 , which verifies this conclusion. Moreover, the larger the tank size is, the smaller the variation of oil temperature presents to the same ambient temperature variation. For the management of oil tank, the large tank size will bring convenience, and the oil storage security is also improved. 

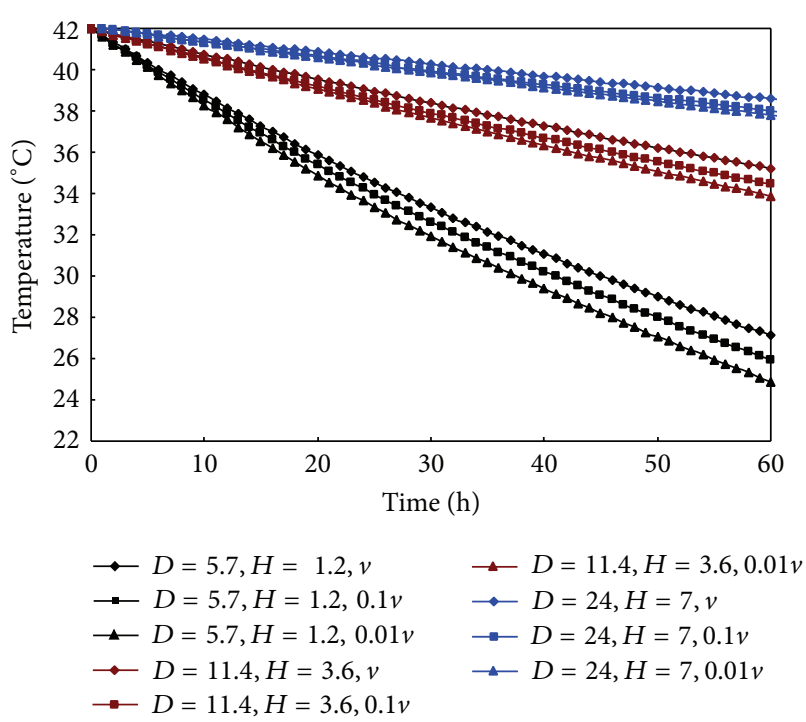

FIGURE 22: Evolution of mean temperature versus viscosity.

In order to investigate the effect of oil properties on cooling rate, the viscosity and specific heat have been taken as two main factors to be examined. To investigate the effect of viscosity, six extra numerical conditions have been performed, which employed two different kinds of viscositytemperature relationships which are, respectively, one and ten percent of the former defined one (in Figure 2) and three kinds of tank sizes used above were also included. Figure 22 clearly shows that for the same tank size, with the increase of viscosity, the natural convection decays, concomitant the reduced heat loss. When the viscosity decreases to 1 percent of the magnitude previously defined (in Figure 2), the mean temperature of oil decreases from $27.1^{\circ} \mathrm{C}$ to $24.9^{\circ} \mathrm{C}$ for the tank size with $D=5.7, H=1.2$ after 60 hours cooling process. And with the increase of tank size, the variation becomes smaller. Thus for the thickened oil with high viscosity, a slower cooling rate and an uneven temperature distribution is expected. Six additional numerical conditions have also been carried out to evaluate the effect of $\mathrm{Cp}$ on cooling rate, as illustrated in Figure 23. The 80 percent and 120 percent of the specific heat defined before (in Figure 3 ) were employed. With the increase of $\mathrm{Cp}$, the larger the heat capacity of oil or the higher the component of wax, the lower the cooling rate. Thus the waxy crude oil should have a much slower cooling rate for the release of latent heat due to the precipitation of wax compositions.

By comparing the above four factors that affect cooling process of waxy crude oil, the tank size is regarded as the most remarkable one. So the centralization storage of crude oil is considered to be a more energy conservation storage pattern. Ambient temperature is another important factor determining the cooling rate which cannot be changed. The effect of crude oil property is not as prominent as the former two. The influence of $\mathrm{Cp}$ presents to be more significant comparing with viscosity on the cooling rate.

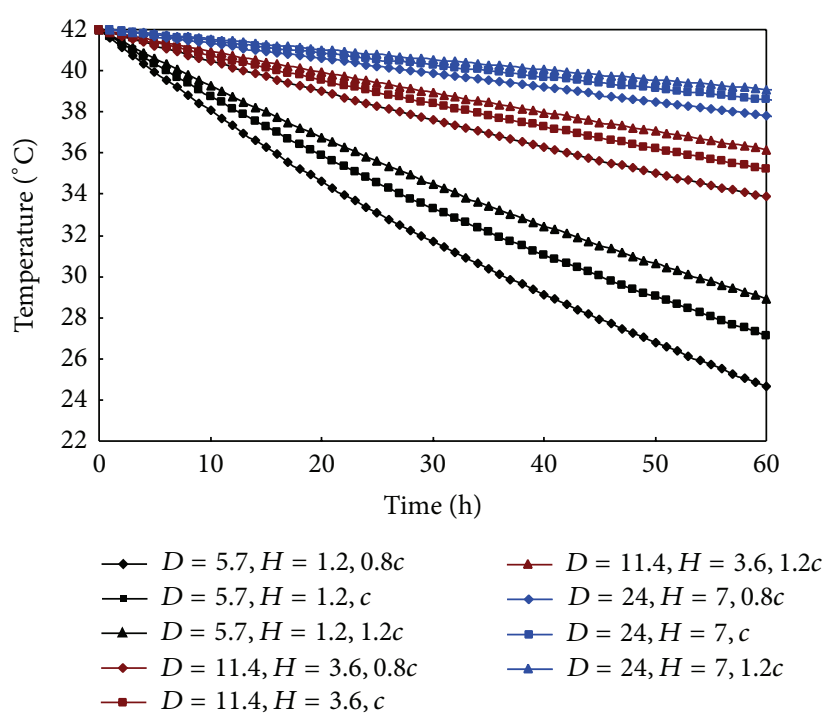

FIGURE 23: Evolution of mean temperature versus Cp.

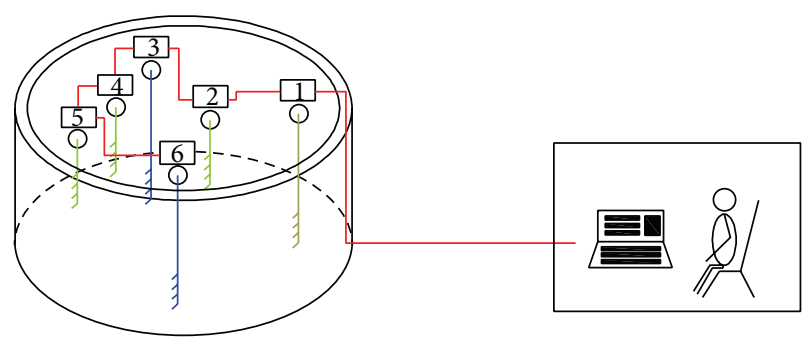

FIGURE 24: The temperature testing system.

\section{Result Verification}

5.1. The Temperature Profile. A temperature testing system has been developed and installed on a floating roof tank of $1 \times 10^{4} \mathrm{~m}^{3}$ in Daqing oil field of China. The testing system is constituted by four parts. The temperature test part which closely contacts with crude oil has been made into a testing rod where multiple temperature sensors unequally distribute, there are six testing rods in total and each one corresponds to a data acquisition device on the roof to collect the resistance signals from the sensors. Some transmission lines have been used to connect each data acquisition and the main module by which the tested data can be displayed and stored real timely. The six testing rods have amounted to 64 temperature sensors located on different positions of the tank, demonstrating the axial and radial profile of temperature. Figure 24 briefly shows the composition of the testing system.

Based on the testing system, the testing work has lasted for about three months in winter. The lowest ambient temperature was $-28^{\circ} \mathrm{C}$. In order to avoid the solidification of waxy crude oil, the heating equipment was activated when the temperature of oil dropped to low. Figure 25 is the temperature profile along the axis direction from the numerical simulation and the testing rod located in the gauge hatch. The profile of oil temperature from testing results mainly agrees well with the numerical results which can also 


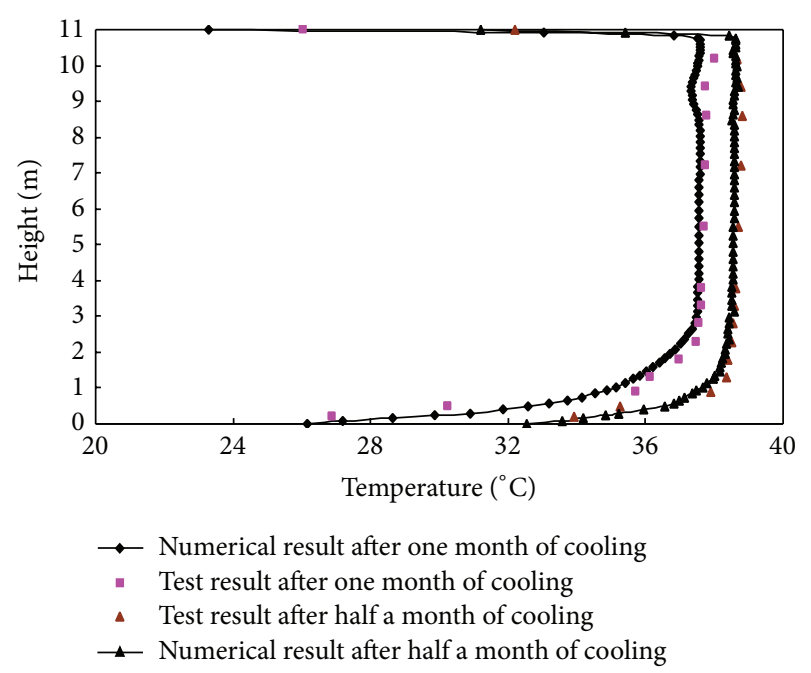

FIGURE 25: The comparison of tested and numerical results.

be divided into three parts; near the top and bottom wall, the temperature is lower than that in the center of the tank. And the low temperature region near the bottom is larger than that near the top wall. The temperature in the core of tank is the highest and is homogeneous. Moreover, comparing the transient temperature distribution after one month and a half, the temperature in the core region dropped slowly; the cooling rate of the top and bottom region was much larger. The most prominent variation is that the cold region enlarged as time marched. In a word, the difference of temperature value between the testing and simulation results presents to be close to each other and the temperature change laws are coincident, thus verifies the numerical simulation results.

5.2. Flow Pattern. Now there is no direct research result for the flow pattern of the unsteady natural convection in floating roof tank. According to the flow pattern of natural convection in dome roof tank proposed by Cotter and Charles [4], due to the predominant heat loss at the sidewall, the convection cell induced by the sidewall plays a dominant role in the tank. However, as the cooling process develops, another small convection cell arises. For the floating roof tank the top wall is the section with the most heat loss; the natural convection must be more complicated.

\section{Conclusions}

The long-term behavior of transient natural convection and heat transfer during the waxy crude oil cooling in a floating roof tank has been deeply investigated by numerical method. Due to the different characteristic, the typical evolution of transient natural convection and temperature distribution are divided into four stages. For the transient natural convection, it can be concluded as the formation, expansion, degradation, and vanishing stage, along with it is the evolution of temperature field which is regarded as the local cooling, integral cooling, the thermal stratification. and heat conduction course. For each stage, the temperature distribution is associated greatly with the natural convection. During the cooling process of waxy crude oil, the first and second stages last very short time, most time is occupied by the third and fourth stages. In view of the safety matter, the third stage becomes the most usual condition during the actual storage process for waxy crude oil.

The precipitation of wax components in crude oil makes difference to the cooling process. On one hand, the waxcrystal structure will be formed and it hinders the movement of oil, thus the convection becomes weak and heterogeneous temperature distribution is obtained. On another hand, the release of latent heat becomes apparent when a mass of wax components separate out. Both variations slow down the cooling rate of oil and the temperature stratification appears more evident. Moreover, for different stages of cooling process, the pattern of solidified oil region is distinguished. And the development of solidified oil region is illustrated in detail. The main characteristic of cooling process obtained from numerical results shows a good agreement with the temperature test results from a large floating tank in the oil depot.

The tank size, the temperature gradient between oil and ambient, the viscosity, and Cp of crude oil are regarded as the main factors on the cooling rate. According to the simulation results from different conditions, Corresponding to the larger tank size, smaller temperature gradient, or higher viscosity and $\mathrm{Cp}$ of crude oil, the cooling rate of oil will be much smaller. Among the four factors, the tank size is regarded as the most remarkable one. So the centralization storage of crude oil is considered to be a more energy conservation storage pattern.

\section{Conflict of Interests}

The authors declare that there is no conflict of interests regarding the publication of this paper.

\section{Acknowledgments}

The authors are grateful to the Nature Science Fund of HeiLongJiang Province for sponsoring this work. In addition, the authors express gratitude to the Key Laboratory of Enhanced Oil and Gas Recovery of Educational Ministry and the Transportation and Storage and Marketing Subsidiary Company of Daqing Oil Field for the support of the temperature test work.

\section{References}

[1] C. Busson and C. Miniscloux, "Modele technoeconomique de calorifugeage des reservoirs de fuel lourd," Revue Générale de Thermique, vol. 226, pp. 785-797, 1980.

[2] J. D. Kumana and S. P. Kathari, "Predict storage tank heat transfer precisely," Chemical Engineering, vol. 89, no. 6, pp. 127132, 1982.

[3] J. E. S. Venart, A. C. Mendes de Sousa, M. Laplante, and R. Pickles, "Free convective flows in large heated oil storage tanks," in Proceedings of the 7th International Heat Transfer Conference, vol. 2, pp. 293-297, 1982. 
[4] M. A. Cotter and M. E. Charles, "Transient cooling of petroleum by natural convection in cylindrical storage tanks. I: development and testing of a numerical simulator," International Journal of Heat and Mass Transfer, vol. 36, no. 8, pp. 2165-2174, 1993.

[5] M. A. Cotter and M. E. Charles, "Transient cooling of petroleum by natural convection in cylindrical storage tanks. II: effect of heat transfer coefficient, aspect ratio and temperaturedependent viscosity," International Journal of Heat and Mass Transfer, vol. 36, no. 8, pp. 2175-2185, 1993.

[6] M. A. Cotter and M. E. Charles, "Transient cooling of petroleum by natural convection in cylindrical storage tanks: a simplified heat loss model," Canadian Journal of Chemical Engineering, vol. 70, no. 6, pp. 1090-1093, 1992.

[7] R. De Césaro Oliveski, M. H. MacAgnan, J. B. Copetti, and A. De La Martinière Petroll, "Natural convection in a tank of oil: experimental validation of a numerical code with prescribed boundary condition," Experimental Thermal and Fluid Science, vol. 29, no. 6, pp. 671-680, 2005.

[8] B. Zhao, "Numerical simulation for the temperature changing rule of the crude oil in a storage tank based on the wavelet finite element method," Journal of Thermal Analysis and Calorimetry, vol. 107, no. 1, pp. 387-393, 2012.

[9] N. Vardar, "Numerical analysis of the transient turbulent flow in a fuel oil storage tank," International Journal of Heat and Mass Transfer, vol. 46, no. 18, pp. 3429-3440, 2003.

[10] R. J. Gross, "An experimental study of single medium thermocline termed energy storage," ASME Report, 1982.

[11] J. Hyun, "Transient process of thermally stratifying an initially homogeneous fluid in an enclosure," International Journal of Heat and Mass Transfer, vol. 27, no. 10, pp. 1936-1938, 1984.

[12] J. E. B. Nelson, A. R. Balakrishnan, and S. Srinivasa Murthy, "Experiments on stratified chilled-water tanks," International Journal of Refrigeration, vol. 22, no. 3, pp. 216-234, 1999.

[13] E. Papanicolaou and V. Belessiotis, "Transient natural convection in a cylindrical enclosure at high Rayleigh," International Journal of Heat and Mass Transfer, vol. 45, no. 7, pp. 1425-1444, 2002.

[14] W. Lin and S. W. Armfield, "Long-term behavior of cooling fluid in a vertical cylinder," International Journal of Heat and Mass Transfer, vol. 48, no. 1, pp. 53-66, 2005.

[15] I. Rodríguez, J. Castro, C. D. Pérez-Segarra, and A. Oliva, "Unsteady numerical simulation of the cooling process of vertical storage tanks under laminar natural convection," International Journal of Thermal Sciences, vol. 48, no. 4, pp. 708-721, 2009.

[16] R. C. Oliveski, A. Krenzinger, and H. A. Vielmo, "Experimental and numerical analysis of a thermal storage tank," Fluid Mechanics and Thermodynamics, vol. 3, pp. 2193-2198, 2001.

[17] R. De Césaro Oliveski, A. Krenzinger, and H. A. Vielmo, "Cooling of cylindrical vertical tanks submitted to natural internal convection," International Journal of Heat and Mass Transfer, vol. 46, no. 11, pp. 2015-2026, 2003.

[18] J. Fernández-Seara, F. J. Uhía, and J. Alberto Dopazo, “Experimental transient natural convection heat transfer from a vertical cylindrical tank," Applied Thermal Engineering, vol. 31, no. 11-12, pp. 1915-1922, 2011.

[19] W. Lin and S. W. Armfield, "Direct simulation of natural convection cooling in a vertical circular cylinder," International Journal of Heat and Mass Transfer, vol. 42, no. 22, pp. 4117-4130, 1999.
[20] S. V. Patankar, Numerical Heat Transfer and Fluid Flow, McGraw Hill, 1980.

[21] B. P. Leonard and S. Mokhtari, Ultra-Sharp Nonoscillatory Convection Schemes for High-Speed Steady Multidimensional Flow, NASA Lewis Research Center, 1999.

[22] R. I. Issa, "Solution of the implicitly discretised fluid flow equations by operator-splitting," Journal of Computational Physics, vol. 62, no. 1, pp. 40-65, 1986. 


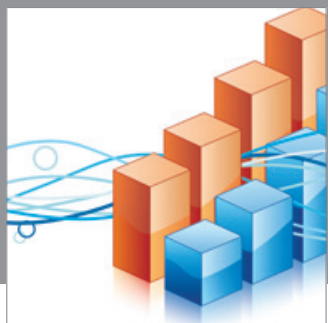

Advances in

Operations Research

mansans

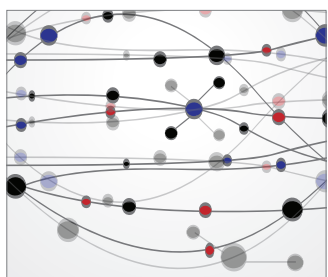

The Scientific World Journal
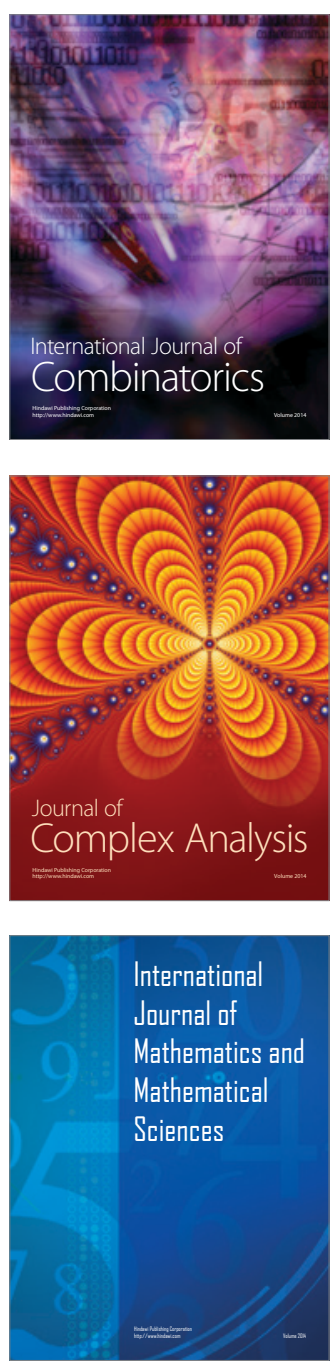
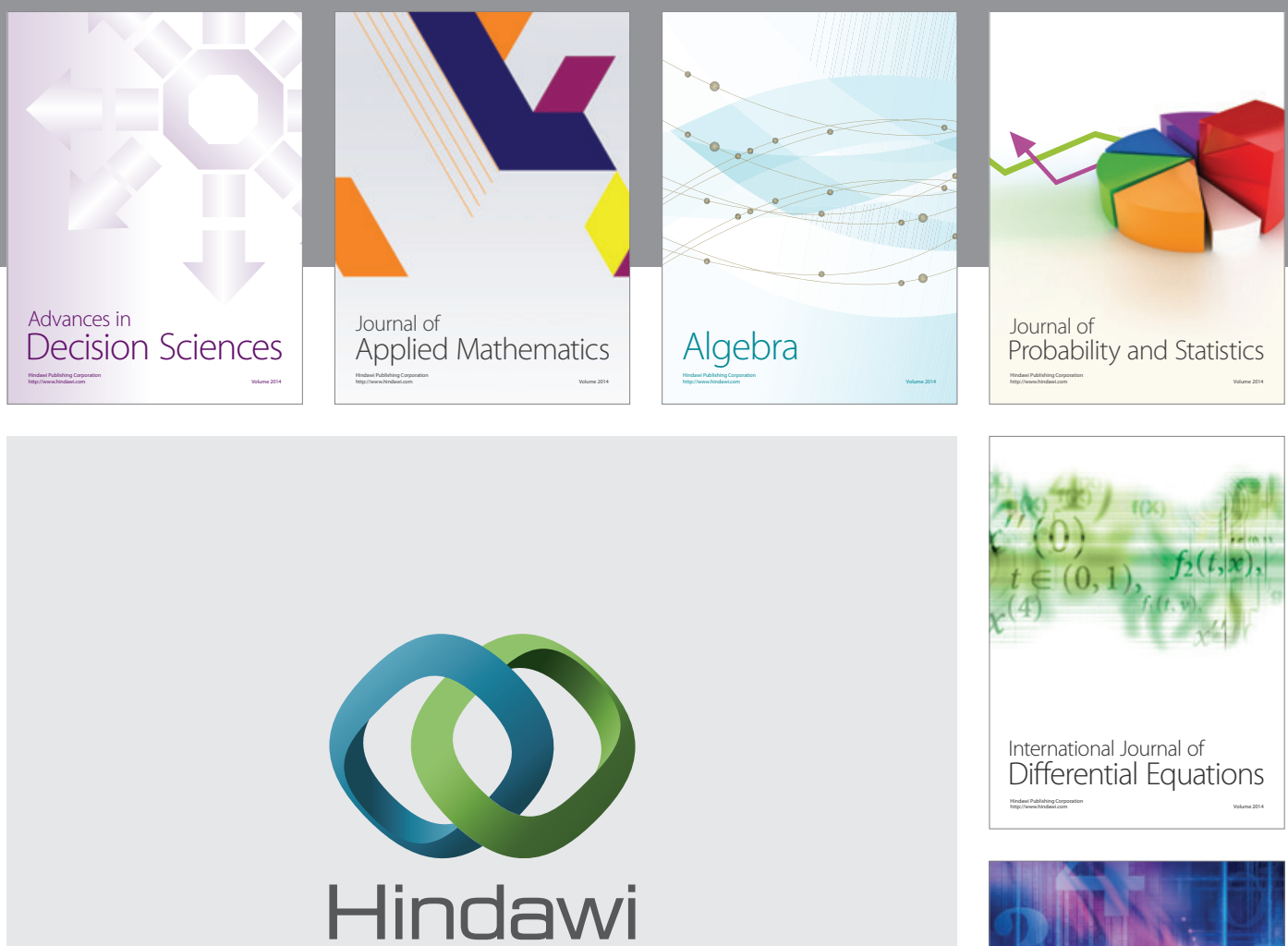

Submit your manuscripts at http://www.hindawi.com
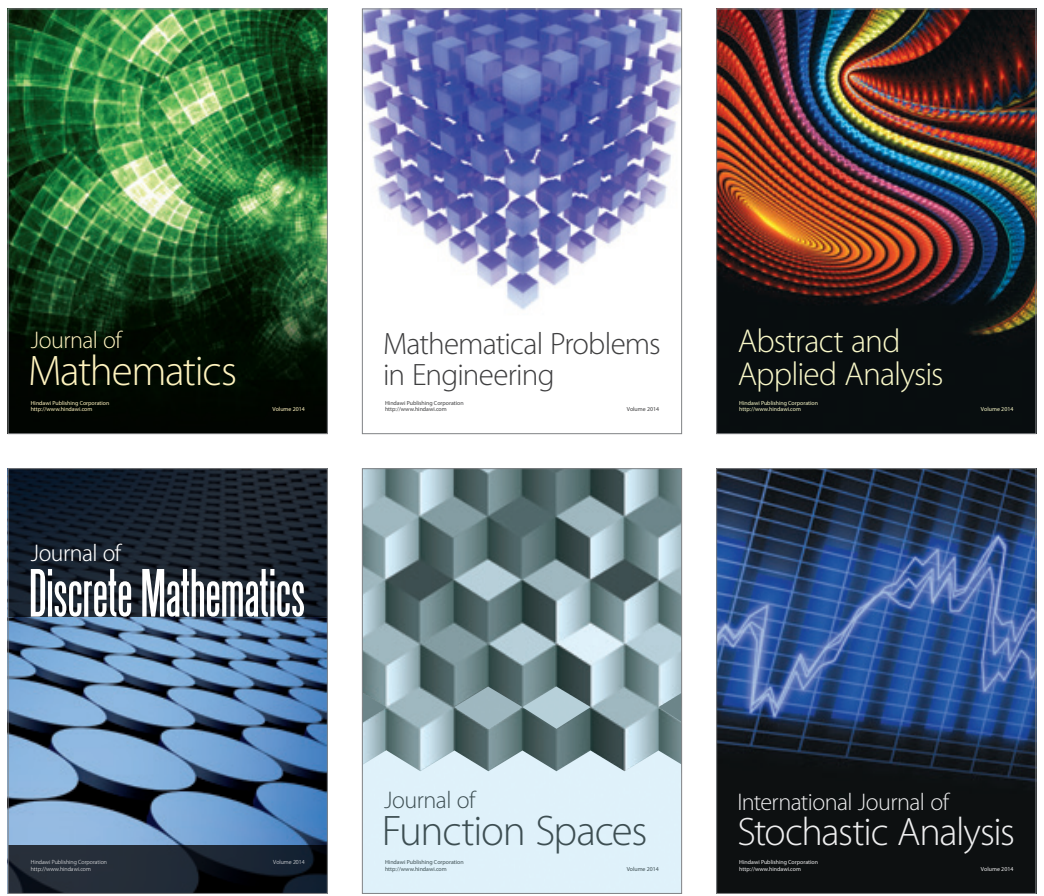

Journal of

Function Spaces

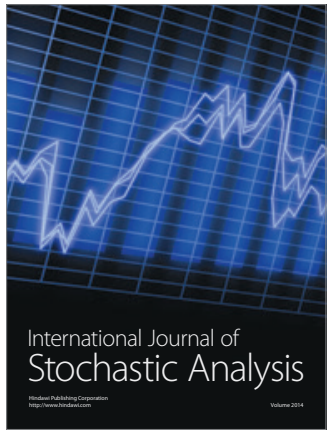

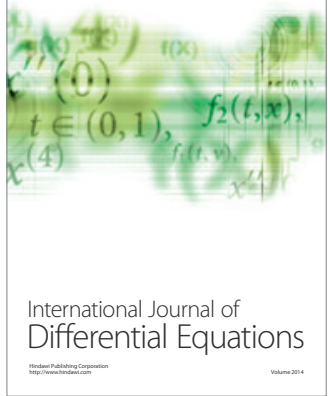
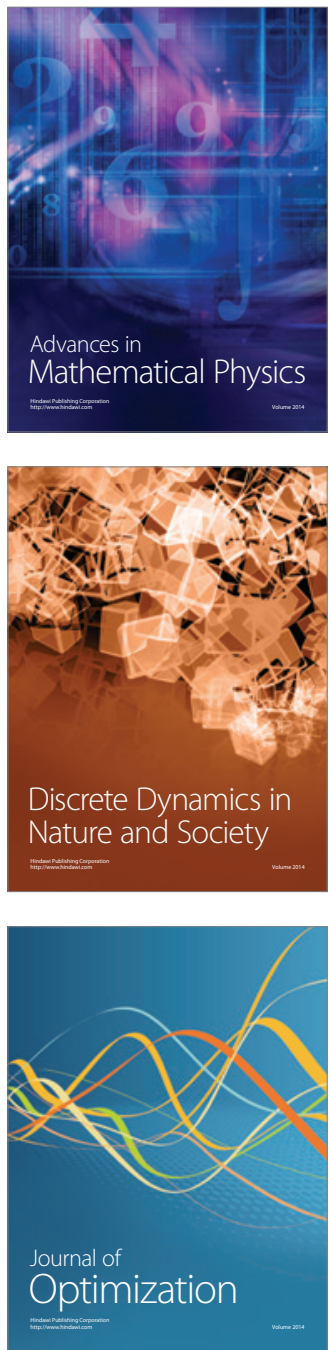